\title{
B cell depletion in immune thrombocytopenia reveals splenic long-lived plasma cells
}

\author{
Matthieu Mahévas,, ${ }^{1,2}$ Pauline Patin, ${ }^{1}$ François Huetz,, 1,3 Marc Descatoire, ${ }^{1}$ Nicolas Cagnard, ${ }^{4}$ \\ Christine Bole-Feysot, ${ }^{5}$ Simon Le Gallou, ${ }^{1}$ Mehdi Khellaf, ${ }^{2}$ Olivier Fain, ${ }^{6}$ David Boutboul, ${ }^{7}$ \\ Lionel Galicier, 7 Mikael Ebbo, ${ }^{8}$ Olivier Lambotte, ${ }^{9}$ Mohamed Hamidou, ${ }^{10}$ Philippe Bierling, ${ }^{11}$ \\ Bertrand Godeau, ${ }^{2}$ Marc Michel, ${ }^{2}$ Jean-Claude Weill, ${ }^{1}$ and Claude-Agnès Reynaud1
}

\begin{abstract}
${ }^{1}$ Faculté de Médecine, Site Necker-Enfants Malades, INSERM U783 Développement du système immunitaire, Université Paris Descartes, Paris, France. ${ }^{2}$ Service de Médecine Interne, Centre de référence des cytopénies auto-immunes de l'adulte, Hôpital Henri Mondor, Assistance Publique-Hôpitaux de Paris, Université Paris Est Créteil, Créteil, France. 3Unité de Biologie des Populations Lymphocytaires, CNRS URA 1961, Institut Pasteur, France.

4Plateforme de bioinformatique de l'université Paris Descartes, Paris, France. ${ }^{5}$ Plateforme de génétique de la fondation Imagine, Hôpital Necker, Paris, France. ${ }^{6}$ Service de Médecine Interne, Hôpital Jean-Verdier, Assistance Publique-Hôpitaux de Paris, Université Paris XIII, Bondy, France.

${ }^{7}$ Service d'Immunopathologie, Hôpital Saint-Louis, Assistance Publique-Hôpitaux de Paris, Université Paris 7 Denis Diderot, Paris, France.

${ }^{8}$ Service de médecine interne, Hôpital de La Conception, Assistance Publique-Hôpitaux de Marseille, Marseille, France. ${ }^{9}$ Service de Médecine Interne,

Hôpital de Bicêtre, Assistance Publique-Hôpitaux de Paris, Le Kremlin-Bicêtre, France. ${ }^{10}$ Service Médecine Interne A, Hôpital Hôtel-Dieu, Nantes, France.

11Établissement Français du Sang, Hôpital Henri Mondor, Assistance Publique-Hôpitaux de Paris, Université Paris Est Créteil, Créteil, France.
\end{abstract}

\begin{abstract}
Primary immune thrombocytopenia (ITP) is a disorder caused by autoantibody-mediated platelet destruction and decreased platelet production. Rituximab, a B cell-depleting agent, has become the first-line treatment for ITP; however, patients with refractory disease usually require splenectomy. We identified antibody-secreting cells as the major splenic $B$ cell population that is resistant to rituximab. The phenotype, antibody specificity, and gene expression profile of these cells were characterized and compared to those of antibody-secreting cells from untreated ITP spleens and from healthy tissues. Antiplatelet-specific plasma cells (PC) were detected in the spleens of patients with ITP up to 6 months after rituximab treatment, and the PC population displayed a long-lived program similar to the one of bone marrow PC, thus explaining for most of these patients the absence of response to rituximab and the response to splenectomy. When analyzed by multiplex PCR at the single-cell level, normal splenic PC showed a markedly different gene expression profile, with an intermediate signature, including genes characteristic of both long-lived PC and proliferating plasmablasts. Surprisingly, long-lived PC were not detected in untreated ITP spleens. These results suggest that the milieu generated by $B$ cell depletion promotes the differentiation and settlement of long-lived PC in the spleen.
\end{abstract}

\section{Introduction}

T cell-dependent immune responses induce the generation of plasmablasts $(\mathrm{PB})$ that migrate to the bone marrow, in which some of them reside for decades as Ig-secreting plasma cells (PC) (1-3). PC have also been described in normal human spleen. In the latter, they display a phenotype similar to that of bone marrow PC, with specific surface marker differences, but their precise life span has not been assessed (4). In addition to bone marrow and spleen, chronically inflamed tissues may also provide a surviving niche for long-lived $\mathrm{PC}$, as shown in the lupus-prone NZBxNZW mouse model (5). The precise phenotype of PC in these different contexts is not established and neither are the signals that drive these cells to reside in one particular niche and to acquire a long-lived program (6).

Primary immune thrombocytopenia (ITP) is an acquired bleeding disorder mediated by pathogenic autoantibodies that enhance platelet destruction and limit their production $(7,8)$. The major target of these autoantibodies is the platelet membrane glycoprotein IIb-IIIa (GpIIbIIIa), but other glycoproteins may be involved (8). The spleen is not only the major site of platelet destruction but is also considered the main site of autoantibody production, thus seemingly containing all the players required to perpetuate the autoimmune reaction $(9,10)$. Accordingly, splenectomy has represented for decades the reference second-line treatment of severe

Conflict of interest: The authors have declared that no conflict of interest exists. Citation for this article: J Clin Invest. 2013;123(1):432-442. doi:10.1172/JCI65689. chronic ITP, resulting in a durable platelet response in two-thirds of patients $(11,12)$.

More recently, anti-CD20-induced B cell depletion, which is used in several autoimmune diseases, has been increasingly used in persistent or chronic ITP prior to splenectomy. Around $40 \%$ of patients with ITP have an initial significant response to the antiCD20 (rituximab) treatment (13) and 20\% have a long-lasting (5 years and more) response (14). Among the remaining patients, who do not respond or have a transient response to rituximab, $60 \%-70 \%$ are cured by splenectomy (13-15). While reports agree on the efficient peripheral $\mathrm{B}$ cell depletion achieved by rituximab treatment, much less is known about B cell depletion in lymphoid tissues and the nature of the resistant pathogenic cells. Moreover, incomplete B cell elimination has been reported in the mouse, either through anti-mouse CD20 treatment $(16,17)$ or in a transgenic human CD20 mouse model treated with rituximab, thus questioning the extent of $\mathrm{B}$ cell depletion achieved in human lymphoid organs $(18,19)$. Possible immunomodulatory roles of rituximab through non-B cell compartments or through antibody-independent mechanisms have also been proposed $(20,21)$.

In this study, we have taken advantage of the different therapeutic strategies and outcomes in patients with ITP to analyze the residual B cell populations present in rituximab-treated spleen and have identified a potentially pathogenic long-lived PC population not targeted by rituximab. Transcriptomic analysis at the population and at the single-cell level, performed on splenic anti- 
body-secreting cells (ASCs) from HDs and from patients treated or not with rituximab, revealed striking differences between these different entities and challenged the accepted views of the environmental conditions that permit the differentiation and residence of long-lived PC.

\section{Results}

Patients with ITP. Characteristics of 15 splenectomized patients with ITP, treated or not with rituximab, are presented in Supplemental Table 1 (supplemental material available online with this article; doi:10.1172/JCI65689DS1). Ten patients, with a median age of 40 years (range, 26-74 years), received 4 weekly infusions of $375 \mathrm{mg} / \mathrm{m}^{2}$ rituximab. All were nonresponsive to rituximab, with platelet counts below $30 \times 10^{9} / 1$ or lower than the double of the baseline count in the month preceding splenectomy. They were splenectomized in the 3 to 6 months following the last rituximab infusion. Four of them received intravenous Igs (IvIg) in the 1-3 weeks preceding the splenectomy. Seven out of ten presented with a complete response, with a follow-up of 7 to 24 months after splenectomy. Five patients with ITP were not treated with rituximab and were splenectomized after a median ITP duration of 24 months. Two of them received IvIg 2 weeks before splenectomy. All were responsive to the splenectomy, with a follow-up of 18 to 30 months. The term "ITP" will be used hereafter for patients not treated with rituximab unless otherwise stated.

The spleen in ITP is the site of an active B cell response. We first investigated the presence of ASCs and germinal center (GC) B cells as hallmarks of an active immune response in the spleens of patients with ITP not treated with rituximab (Figure 1A and Supplemental Table 2). The major part of the ASC population in these patients expressed the Ki67 cell cycle marker and were HLA-DR hi, i.e., displayed a PB phenotype. Overall, PB were markedly increased in the spleens of these patients (Figure 1B). PC were slightly but not significantly increased compared with healthy donors (HDs) (Figure 1C). Similarly, the GC B cell population was also significantly expanded in these ITP spleens (Figure 1D). By confocal microscopy analysis, we found numerous GC structures within secondary follicles in all ITP spleens examined $(n=3)$ (Figure 1E), whereas mainly primary follicles were observed in splenic samples from HDs $(n=3)$ (Figure 1F). PB were found in these ITP spleens (Figure 1, $\mathrm{G}$ and $\mathrm{H}$ ) but were rarely detectable in HDs, with a wide distribution from the GC area to the red pulp. Numerous proliferating $\mathrm{T}$ cells were also observed in the patient with ITP and not in the HD (Figure 1, I and J). Altogether, our data indicate that the spleen is the site of an unusually active B cell response in patients with ITP.

Presence of anti-GpIIbIIIa IgG-producing cells in ITP spleens. We next investigated the ability of ASCs to produce autoantibodies in vitro. We used the previously described anti-GpIIbIIIa ELISPOT assay in order to quantify the fraction of autoreactive ASCs (9). In all but one spleen, we observed GpIIbIIIa-specific spots, ranging from $0.5 \%$ to $1.2 \%$ of total IgG-secreting cells (Figure $1 \mathrm{~K}$ and Supplemental Table 2). No anti-GpIIbIIIa IgG-secreting cells were observed in HDs (Figure 1L). After a 5-day culture of ITP spleens without stimulation, anti-GpIIbIIIa IgG-secreting cells were still observed with an increase of the size and the intensity of the spots (data not shown), reflecting the robustness of the response. All patients responded to the splenectomy, including the one showing a negative anti-GpIIbIIIa IgG ELISPOT.

Splenic residual B cells in patients with primary failure of rituximab are mainly $P C$ and some of them are autoreactive. In order to study the residual B cells that survived the rituximab-suppressive action, we focused on rituximab-treated patients who did not respond and had been subsequently splenectomized within the 3-6 months after the last rituximab infusion, i.e. before the reemergence of newly formed B cells.

As extensively described, B cells were scarcely detectable in peripheral blood $\left(<0.1 \%\right.$ of $\mathrm{CD} 45^{+}$cells) (Table 1$)$. We did not observe any dividing $\mathrm{Ki}^{+} 7^{+}$cells; all cells expressed the CD27 marker, and more than 50\% expressed IgA isotypes as previously described (data not shown) (22). By contrast, analysis of the 10 spleens from rituximab-treated patients revealed that $0.5 \%$ of $\mathrm{CD} 45^{+}$mononuclear cells were B cells (Table 1). Further analysis showed that these rituximab-resistant B lineage cells could be separated in two populations: memory B cells and PC (Figure $2 \mathrm{~A})$. No dividing $\mathrm{Ki} 67^{+}$cells were observed. In all but one rituximab-treated patient, $\mathrm{PC}$ were the main residual population (Figure 2B). As described for normal splenic samples (4), splenic PC from rituximab-treated patients (RTX-PC) did not express CD138 in contrast with bone marrow $\mathrm{PC}$ and did not downregulate CD19, as $92 \%-98 \%$ of CD $27^{+} \mathrm{CD} 38^{\text {hi }}$ cells were CD $19^{+}$. RTX-PC were characterized as $\mathrm{CD} 38^{\text {hi }} \mathrm{CD} 20^{-} \mathrm{Ki}^{-} 7^{-} \mathrm{HLA}-\mathrm{DR}^{\mathrm{lo}} \mathrm{CD}^{+}$cells (Figure $2 \mathrm{~A}$ ) and expressed splenic PC surface markers, such as CD86 and CD11a (ref. 4 and Supplemental Figure 1A). Patients who responded to splenectomy (7 out of 10) tended to have a higher number of PC in the spleen, as compared with nonresponders (Figure 2C), although this difference failed to reach significance due to the small number of patients in each category $(P=0.066)$

We used the ELISPOT assay to determine whether some residual PC were autoreactive (Figure 2C). Residual PC expressed IgM, IgG, and IgA isotypes (Supplemental Figure 1B). We observed antiGpIIbIIIa IgG-secreting cells in 7 out of 10 patients, with a frequency ranging from $0.25 \%$ to $4 \%$, but we failed to identify antiGpIIbIIIa IgM- or IgA-secreting cells (Table 1). Six out of these seven patients presenting GPIIbIIIa-specific PC responded to the splenectomy, while specific spots were detectable in a patient who failed to respond (Figure 2, D and E).

Overall, these findings suggested that the failure of rituximab treatment could be explained in the majority of the patients by the presence of residual autoreactive anti-GpIIbIIIa PC in the spleen.

Residual PC in patients with primary failure of rituximab display a longlived genetic program. In patients with a primary failure of rituximab, the persisting splenic $B$ cells are nondividing and contain minimal numbers of memory B cells, thus suggesting that the residual PC observed have been generated before the rituximab-induced depletion and were thus long lived. To test this hypothesis, we performed a transcriptome analysis to compare the gene expression profiles of the various splenic ASC subsets from patients and controls. We sorted PC and PB from 3 HDs and 3 patients with ITP, using HLADR expression to discriminate between them (gating strategy: Supplemental Figure 2), as well as PC from 4 rituximab-treated patients. We first focused on the 2 major subsets from patients, i.e., PB from patients with ITP (ITP-PB) and RTX-PC, which could be sorted to high purity due to their predominance in each category of patients. We performed a supervised analysis and identified 609 differentially expressed genes ( $P<0.05$, $>4$-fold change). The genes overexpressed in RTX-PC compared with those in ITPPB were antiapoptotic genes (BCL2, CFLAR, TNFAIP3, BIRC3); negative regulators of the cell cycle and notably several members of the family of Kruppel-like factors (KLF2, KLF6, KLF9, KLF15); transcription factors (FOS, JUN, JUNB, RORA); genes related to the 
A
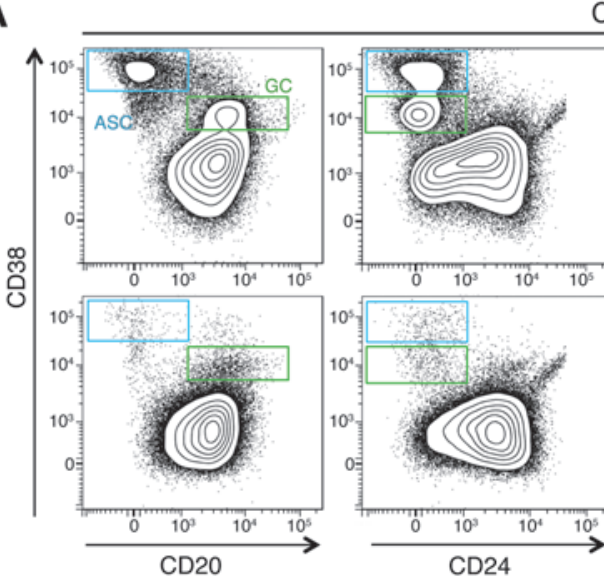

CD19+
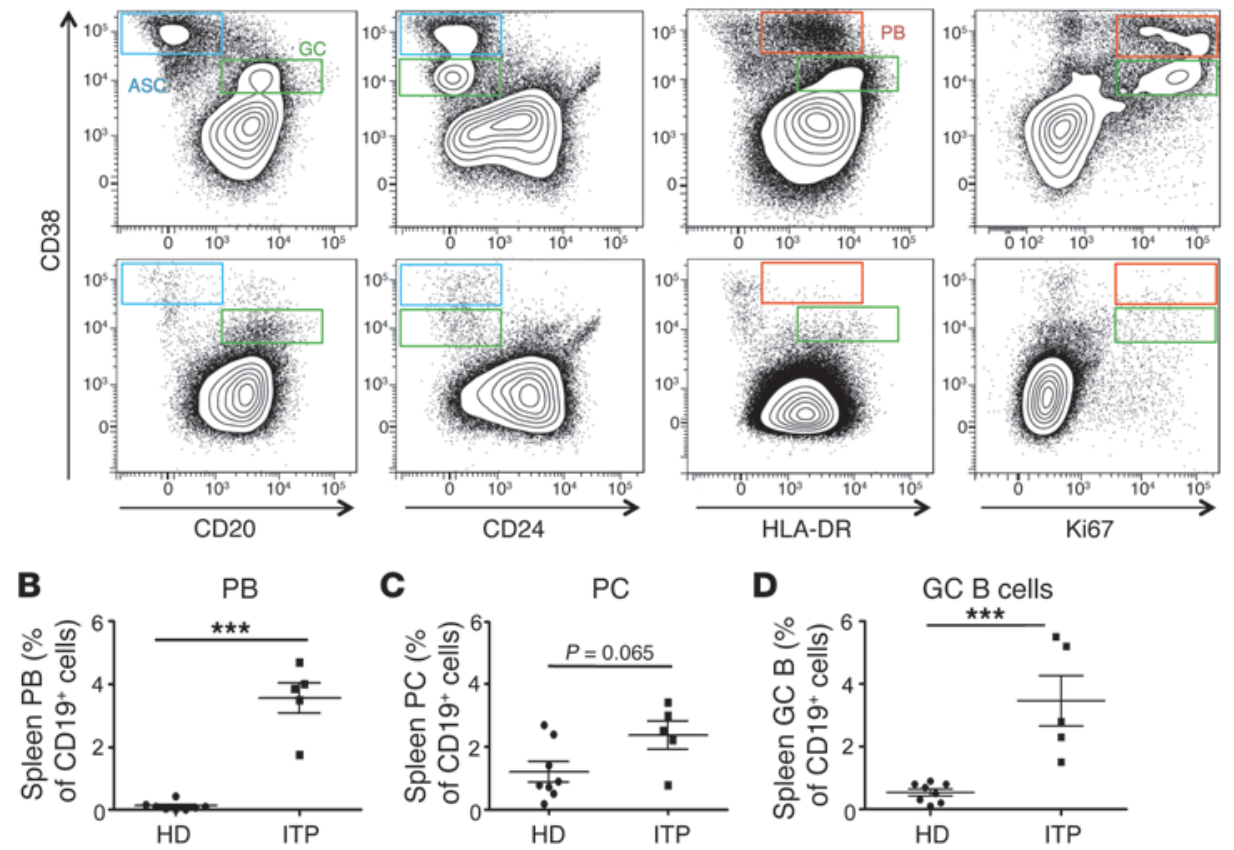

ITP
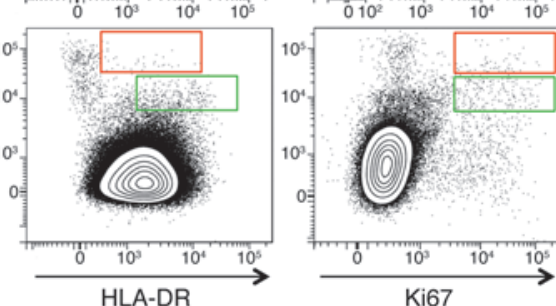

HD

C
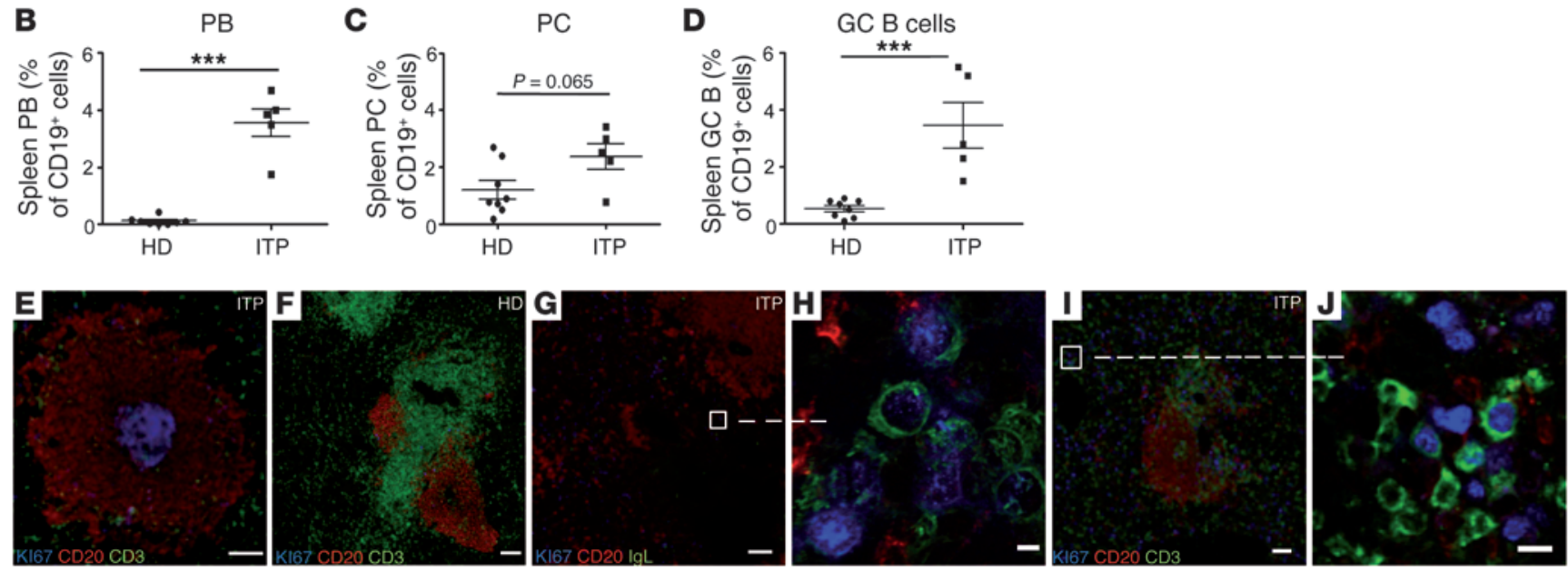

$\mathbf{K}$
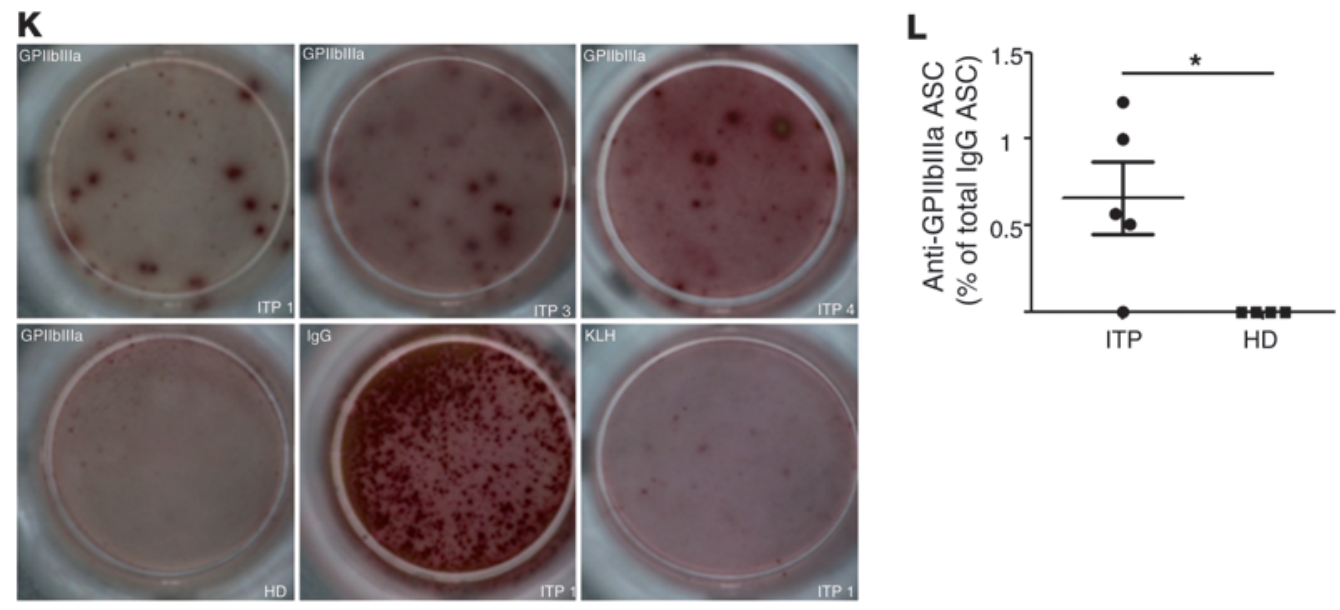

$\mathrm{HD}$

Figure 1

Spleen in ITP is the site of an active B cell response producing anti-Gpllbllla-specific ASCs. (A) Flow cytometry analysis of splenic mononuclear cells labeled with antibodies to CD19, CD38, CD20, CD24, HLA-DR, and Ki67. After gating on CD19+ cells, ASCs were identified as CD20-,

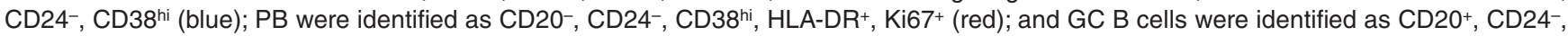
CD38+, Ki67+ (green). (B-D) Numbers of splenic (B) PB, (C) PCs (identified as CD19+CD20-CD24-CD27+CD38hiKi67-), and (D) GC B cells in patients with ITP $(n=5)$ compared with HD $(n=8)$. (E-J) Analysis by confocal microscopy of spleen sections from a patient with ITP (ITP1) and a $\mathrm{HD}$ (17 years old) using anti-CD3, anti-CD20, anti-Ki67, and anti-IgL (anti- $/ \lambda$ light chains) antibodies. (E) Secondary follicles with proliferating GC B cells, (G, box enlarged in H) PB $\left(C D 20^{-}, \lg \kappa / \lambda^{+}, K_{i 67^{+}}\right)$, and (I, box enlarged in $\left.\mathbf{J}\right) \mathrm{T}$ cells $\left(\mathrm{CD}^{+} \mathrm{Ki}^{+}\right)$in patient with ITP and (F) primary follicles in HD. Scale bars: $100 \mu \mathrm{m}(\mathbf{E}-\mathbf{G}$ and I); $5 \mu \mathrm{m}$ (H and $\mathbf{J})$. Data are representative of 3 ITP and HD samples. (K) ELISPOT quantification of anti-Gpllbllla IgG-secreting cells in 3 ITP (top) and $1 \mathrm{HD}$ (bottom left) among total IgG-secreting cells (bottom middle), with KLH as antigen control (bottom right). (L) Frequency of anti-GPIlbllla IgG-secreting cells in patients with ITP $(n=5)$ compared with HD $(n=4)$. Two-tailed Mann-Whitney tests $\left({ }^{\star \star \star} P<0.001 ;{ }^{*} P=0.044\right)$. Symbols indicate individual samples; horizontal bars represent mean values $( \pm$ SEM). 
Table 1

Number and repartition of residual blood and spleen B cells and spleen IgG and anti-GPIIbIIla ASC in rituximab-treated patients

\begin{tabular}{|c|c|c|c|c|c|c|}
\hline Patients & $\begin{array}{l}\text { Blood B cells/ } \\
\text { CD45 }^{+} \text {cells }\end{array}$ & $\begin{array}{l}\text { Spleen B cells/ } \\
\text { CD45 }^{+} \text {cells }\end{array}$ & $\begin{array}{c}\text { Absolute no. of } \\
\text { spleen } \mathrm{PC} / 10^{6} \text { cells }^{\mathrm{A}}\end{array}$ & $\begin{array}{l}\text { Spleen PC/ } \\
\text { CD19+ cells }{ }^{A}\end{array}$ & $\begin{array}{l}\text { Absolute no. of lgG- } \\
\text { secreting cells } / 10^{6} \text { cells }^{B}\end{array}$ & $\begin{array}{l}\text { Anti-Gpllbllla } \\
\text { ASC/total IgGB }\end{array}$ \\
\hline RTX 1 & - & $0.75 \%$ & 3,781 & $67 \%$ & 1,344 & $2.0 \%$ \\
\hline RTX 2 & - & $0.54 \%$ & 2,736 & $68 \%$ & 1,200 & $3.0 \%$ \\
\hline RTX 3 & $0.04 \%$ & $0.47 \%$ & 524 & $33 \%$ & 600 & $4.0 \%$ \\
\hline RTX 4 & - & $0.48 \%$ & 1,330 & $55 \%$ & 1,020 & $<0.05 \%$ \\
\hline RTX 5 & - & $0.06 \%$ & 378 & $92 \%$ & 360 & $<0.1 \%$ \\
\hline RTX 6 & - & $1.0 \%$ & 5,053 & $97 \%$ & 1,810 & $0.25 \%$ \\
\hline RTX 7 & $0.03 \%$ & $0.17 \%$ & 834 & $82 \%$ & 420 & $0.25 \%$ \\
\hline RTX 8 & - & $0.20 \%$ & 1,344 & $96 \%$ & 688 & $0.88 \%$ \\
\hline RTX 9 & $0.07 \%$ & $0.51 \%$ & 2,116 & $61 \%$ & 1,601 & $0.84 \%$ \\
\hline RTX 10 & $0.02 \%$ & $0.19 \%$ & 1,285 & $98 \%$ & 1,224 & $<0.1 \%$ \\
\hline
\end{tabular}

ADetermined by FACS analysis. BDetermined by ELISPOT assay.

unfolded protein response (Dnaj, HSPB1, MAFF, ATF3); and genes encoding adhesion molecules or surface receptors (ICAM1, CD9, IL5R, IL6ST). On the other part, RTX-PC underexpressed, as compared with ITP-PB, genes implicated in positive regulation of the cell cycle (BIRC5, CENPF, BUB1, BUB1B, ZWINT, MCM4, MKI67); genes encoding adhesion molecules (S1PR1, CD58); and activating molecules like TLRs (TRL10, TLR7) (Figure 3). Thus, RTX-PC expressed a specific genetic program consistent with a quiescent, long-lived phenotype.

The gene expression profile of $P C$ from $H D$ s differs from the one of $R T X$ $P C$. PB from patients with ITP and PC from rituximab-treated patients represent two opposites of the ASCs differentiation pathway. To position PC from HDs along this maturation scale, we compared the gene expression profile of $\mathrm{PC}$ from HDs to that of both ITP-PB and RTX-PC for the 609 discriminating genes described previously (Figure 3). For 267 of these genes, the expression was similar between RTX-PC and HD-PC, while for 99 of them, HD-PC expression was similar to that of ITP-PB ( $<2$-fold change). Among the genes shared by HD- and RTX-PC were upregulated genes: transcription factors (JUN, JUNB, FOS), antiapoptotic genes (BIRC3), and adhesion molecules (CD9, ICAM1). Among genes with a similar low expression between HD-PC and ITP-PB were negative cell cycle factors (KLF4, KLF6, and KLF9). Forty-two genes were significantly different $(>2$-fold change, $P<0.05$ ) between HD-PC and both RTX-PC and ITP-PB, among which were BCL2 and cell cycle regulators/markers $B U B 1, C D C 6, C E N P F, M K I 67$, and $M C M 4$. The gene expression profile of normal $\mathrm{PC}$ thus appears intermediate between RTX-PC and ITP-PB.

Single-cell gene expression analysis of $H D$ - $P C$ reveals an intermediate gene expression profile between RTX-PC and ITP-PB. The intermediate profile revealed by the HD-PC transcriptome analysis could be due either to a unique population with such an intermediate profile or to a mixed population of long-lived PC and short-lived PB. To address this issue, we performed a single-cell gene expression analysis of splenic ASC subsets from patients and controls. We sorted PC from 2 HDs and 2 rituximab-treated patients as well as PB from 2 patients with ITP according to the HLA-DR expression criterion (see above). We selected 15 genes from the transcriptome analysis that discriminated PB from PC (BIRC5, BUB1, MKI67, ZWINT, CDC6, CCND2, CENPF, KLF6, KLF9, FOS, TNFAIP3, BIRC3, $A T F 3, C D 9$, and SOCS1 as well as B2M as control). Single-cell gene expression profiling was performed by multiplex RT-PCR using
Fluidigm Dynamic Arrays, and data were processed by a principal component analysis (PCA). PCA reduces the complexity of a multivariate analysis to a few components (here 3 ), capturing a large part of the variance (depicted for each axis, see Figure 4A) through a linear combination of these variables. PCA of the single-cell gene expression profile revealed that RTX-PC and ITP-PB segregated in 2 distinct populations, either normalized or not with the $B 2 M$ housekeeping gene (Figure 4A and Supplemental Figure 3). The major fraction of HD-PC showed an intermediate profile that differed from that of RTX-PC and ITP-PB. A few cells clustered with the RTX-PC or ITP-PB population. We then selected 8 genes for further analysis: 4 cell cycle genes (BUB1, MKI67, ZWINT, CENPF, highly expressed in ITP-PB and at background level in RTX-PC) and 4 cell cycle regulators/antiapoptosis genes (KLF6, KLF9, TNFAIP3, ATF3, highly expressed in RTX-PC and expressed at a lower level in ITP-PB). Similar results were obtained for the PCA using this set of genes (Figure 4B). Based on their qualitative expression, we further classified each single cell with a "PB signature" (>1 cell cycle gene and $\leq 1$ upregulated PC genes) or a "PC signature" (no cell cycle gene and $>1$ upregulated PC genes) or as "unclassified." These differential criteria were selected to match the transcriptional characteristics of the genes in the 2 categories: an on/off expression for cell cycle genes and a low/high expression for PC-specific genes in ITP-PB vs. RTX-PC. According to these criteria, $84 \%$ of RTX-PC showed a "PC signature" and 75\% of ITP$\mathrm{PB}$ showed a "PB signature." In contrast, $75 \%$ of individual HD-PC were "unclassified," with a "PC signature" identified for less than $15 \%$ of them (Figure 4C). Thus, RTX-PC are a unique long-lived population from which the major part of HD-PC differ.

ITP-PC analyzed at the single-cell level do not display a long-lived program. To ask whether the presence of long-lived PC in rituximab-treated spleens could be contributed to by the autoimmune inflammatory environment, we analyzed PC from patients with ITP (not treated with rituximab) using the same single-cell multiplex PCR approach. PCA based on the expression profile of the 15 genes described previously indicated that, as for HD-PC, the PC present in patients with ITP showed an intermediate phenotype between long-lived PC and proliferating PB (Figure 4D). It seems therefore that the generation of the long-lived PC in spleens of rituximab-treated patients does not result from a previous inflammatory state.

Splenic ASC from patients with ITP display a specific genetic signature characterized by downregulation of SOCS3. To identify disease-spe- 
A
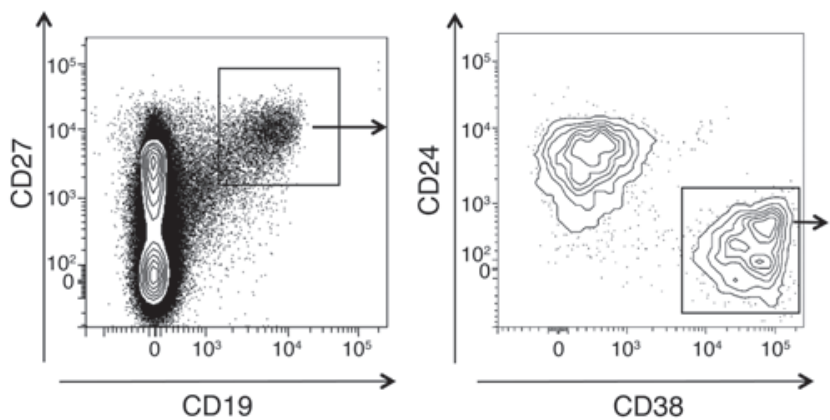

B
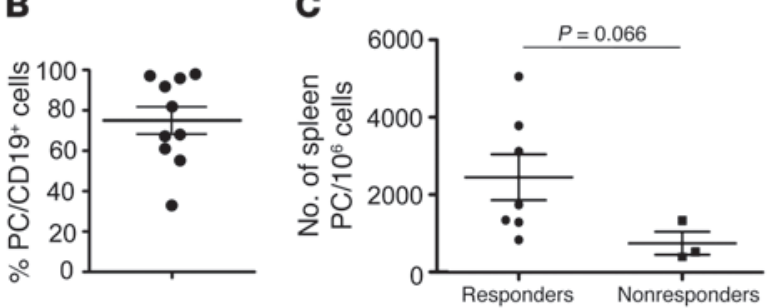

E

줌

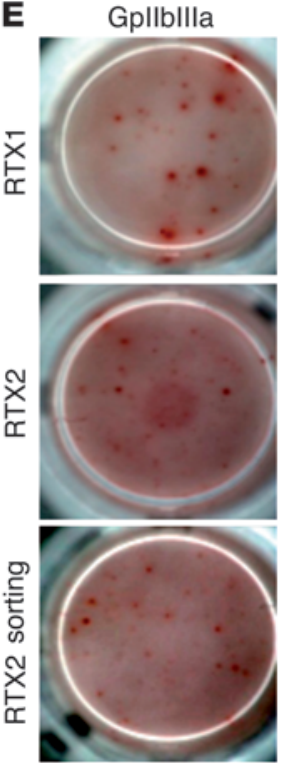

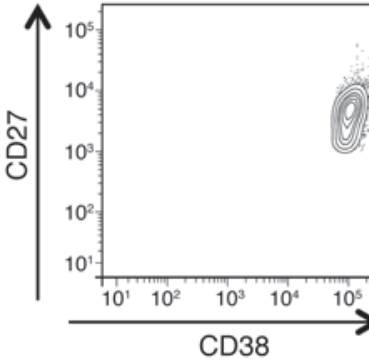
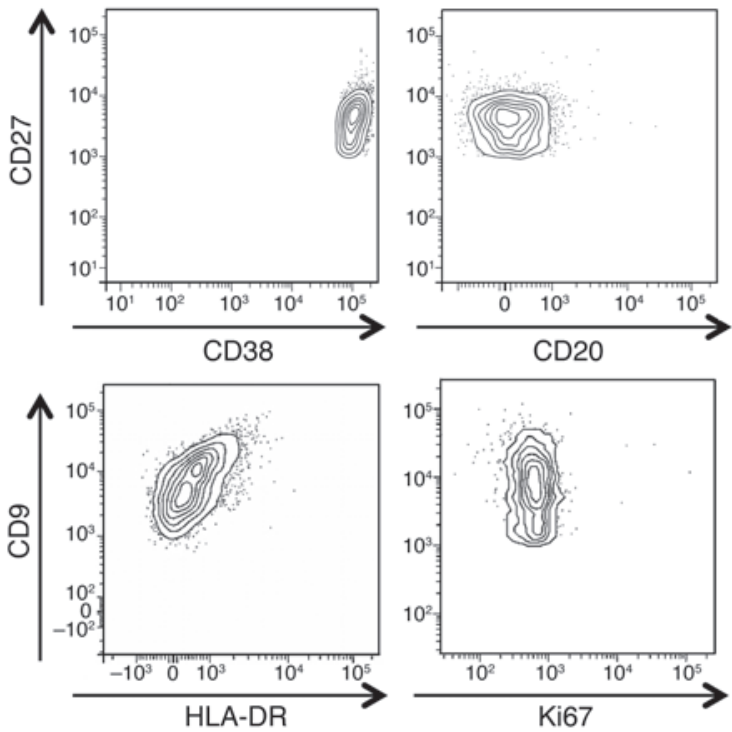

D

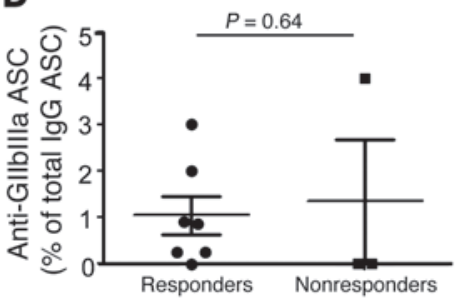

Figure 2

Autoreactive PC in patients with primary failure of rituximab. (A) Flow cytometry analysis of splenic mononuclear cells, labeled with anti-CD19, CD38, CD20, CD24, CD27, CD9, HLA-DR, and Ki67 antibodies. All residual splenic $B$ cells were $\mathrm{CD} 19^{+} \mathrm{CD} 27^{+}$and included memory B cells (CD24+CD38-) and PC (CD24-CD38 $\left.{ }^{\text {hi }}\right)$ (blue gate), further identified as CD20-HLA-DR ${ }^{\circ} \mathrm{Ki} 67^{-} \mathrm{CD} 9^{+}$. (B) Percentage of PC per CD19 cells for each patient (mean, $74.9 \%$ [range, 33-98]). (C) Absolute numbers of spleen PC in rituximab-treated patients, segregated as responders and nonresponders to the splenectomy. Two-tailed Mann-Whitney test $(P=0.066)$. (D) Frequency of anti-Gpllbllla IgG-secreting cells in responders or nonresponders to the splenectomy. Two-tailed Mann-Whitney test $(P=0.64)$. (E) ELISPOT quantification of anti-Gpllbllla IgG-secreting cells in 2 rituximab-treated patients among total IgG-secreting cells, with $\mathrm{KLH}$ as antigen control, estimated from $1 \times 10^{6}$ total spleen cells (RTX1 and RTX2) or $2 \times 10^{4}$ cell-sorted PC (RTX2, sorting of $\mathrm{CD} 19^{+} \mathrm{CD} 27^{+} \mathrm{CD} 38^{\text {hi }}$ cells). The dilution factor is indicated for IgG-positive spot detection. Symbols indicate individual samples; horizontal bars represent mean values $( \pm$ SEM).

cific genes, we extracted 158 probes that discriminated all patient subsets (ITP-PC [ $n=3]$, ITP-PB [ $n=3]$, and RTX-PC [ $n=4]$ ) from control subsets (HD-PC $[n=3]$ and $\mathrm{PB}[n=2]$ ) (>2-fold change, $P<0.01)$. The 12 most striking genes are shown in Figure 5A. ASC in HDs overexpressed SOCS3 as well as PTP4A3 (also known as PRL-3; involved in CXCL12-mediated migration of multiple myelomas, and, together with SOCS3, defining a multiple myeloma subtype) (23), in contrast with ASC from patients with
ITP that expressed both genes minimally (a 50-fold difference). RT-PCR confirmed that low expression of SOCS3 is a hallmark of ITP ASC (Figure 5B). Contradictory data have been reported concerning the impact of SOCS 3 on cell migration. Two groups described a negative feedback control of SOCS3 on the CXCR4 signaling function $(24,25)$; on the other hand, Tarlinton and colleagues, while reporting a prolonged STAT3 signaling induced by IL-6 stimulation of SOCS3-deficient PC, observed no impact 
ITP-PB HD-PC RTX-PC
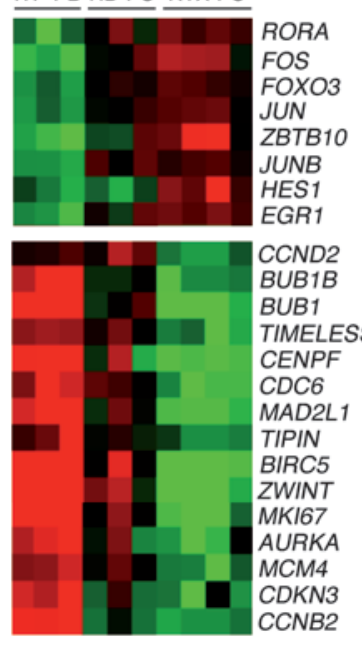

CCND2

CCND2
BUB1B

BUB1

TIMELESS

CENPF

CDC6

MAD2L1

TIPIN

BIRC5

ZWINT

MKI67

AURKA

MCM4

CDKN3

CCNB2

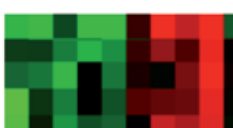

KLF4

KLF2

PPP1R15A

KLFG

GADD45B

MTUS1

KLF11

LATS2

TSPYL2

KLF15

KLFO

SESN1

SOCS1

CDKN1C

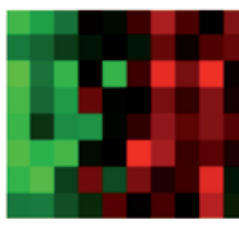

$B C L 2$

CFLAR

TNFAIP3

BIRC3

PRNP

FAS

IER3

VEGFA
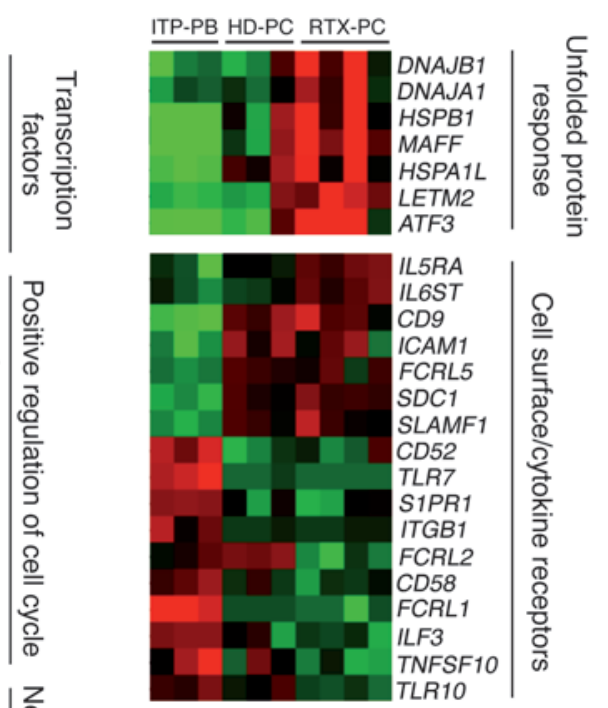

ATF3

underexp overexp

\section{Figure 3}

Transcriptional analysis of ITP-PB, HD-PC, and RTX-PC reveals a specific long-lived gene expression profile for RTX-PC. Heat map clustering of genes selected from the supervised comparison of RTX-PC vs. ITP-PB (609 probes with a fold change $>4$ or $<0.25$ and $P<0.05$ ), classified as transcription factors, positive regulation of cell cycle, negative regulation of cell cycle, antiapoptosis, unfolded protein response, and cell surface/cytokine receptors. Columns represent individual samples and rows represent specific gene probes, with upregulated genes in red and downregulated genes in green (2-fold scale indicated). Complete data sets of the comparisons between RTX-PC and ITP-PB as well as between RTX-PC and HD-PC are included in Supplemental Tables 3 and 4. of SOCS3 gene inactivation on CXCL12-induced migration of mouse B cells (26).

Interestingly, a higher expression of the CXCR4 gene was observed in ASC from patients with ITP compared with those from HD (Figure 5A), but cell surface expression of CXCR4 was similar between them (data not shown).

$R T X-P C$ are nonmigratory cells that display a resident phenotype. In order to find out whether the overexpression of CXCR4 and downregulation of SOCS3 and PRL-3 may have an impact on PC or PB migration toward CXCL12, we studied ASC migration by culturing total spleen cells with or without CXCL12. We observed that $30 \%$ of ASC migrated toward CXCL12 in ITP samples and $20 \%$ of ASC migrated toward CXCL12 in control samples, with a fraction of cells migrating without cytokines, as previously described (ref. 27 and Figure 5C). The migratory population expressed high levels of HLA-DR at the surface, suggesting that it had a PB phenotype (data not shown). By contrast, RTX-PC were non migratory toward CXCL12, whatever the duration of cell culture $(6,12,24$ hours). RTX-PC did not express CXCR3, CD62L, or CCR10 (data not shown) but expressed CCR2, the receptor for CCL2 (see below), and the adhesion molecules CD44, CD11a, and CD9 (Supplemental Figure 1A). RTX-PC are thus nonmigratory and display a resident phenotype.

ASC survival in ITP is increased, suggesting a role for the proinflammatory environment. We next wanted to assess whether the genetic signature observed could be correlated to the inflammatory ITP microenvironment. Both ASC from rituximab-treated patients and patients with ITP showed an increased survival compared with that of ASC from HD upon in vitro culture $(P<0.01)$ (Figure $6 \mathrm{~A})$. If the better persistence of ASC from rituximab-treated spleens is likely to reflect their intrinsic survival capacity in vitro, it might rather correspond, for ITP-PB, to a maintenance contributed by proliferation. We next investigated whether specific cytokines could be involved and released in the culture medium. In a panel of 27 cytokines, we did not observe a bias for TH1 or $\mathrm{TH} 2$ cytokines, either in ITP or rituximab-treated patients (data not shown). By contrast, BAFF secretion was increased 2 fold in rituximab spleen supernatants compared with that in ITP spleens $(P<0.05)$ (Figure 6B); IL-6 was increased in 3 out of 4 ITP spleens compared with controls but not in rituximab samples $(P<0.05)$ (data not shown). There was no difference in APRIL secretion in rituximab and/or ITP spleen supernatants compared with those from HD (data not shown). CCL2 (also known as MCP-1) was significantly increased in both ITP and rituximab spleen cultures compared with that in HD cultures (Figure 6C), and its receptor, CCR2, was expressed at the RTX-PC surface. CCL2 has been shown to recruit monocytes, neutrophils, or basophils at inflammation sites. Accordingly, among other cell types tested, basophils numbers were increased in rituximab $(P<0.01)$ and in ITP $(P<0.05)$ 

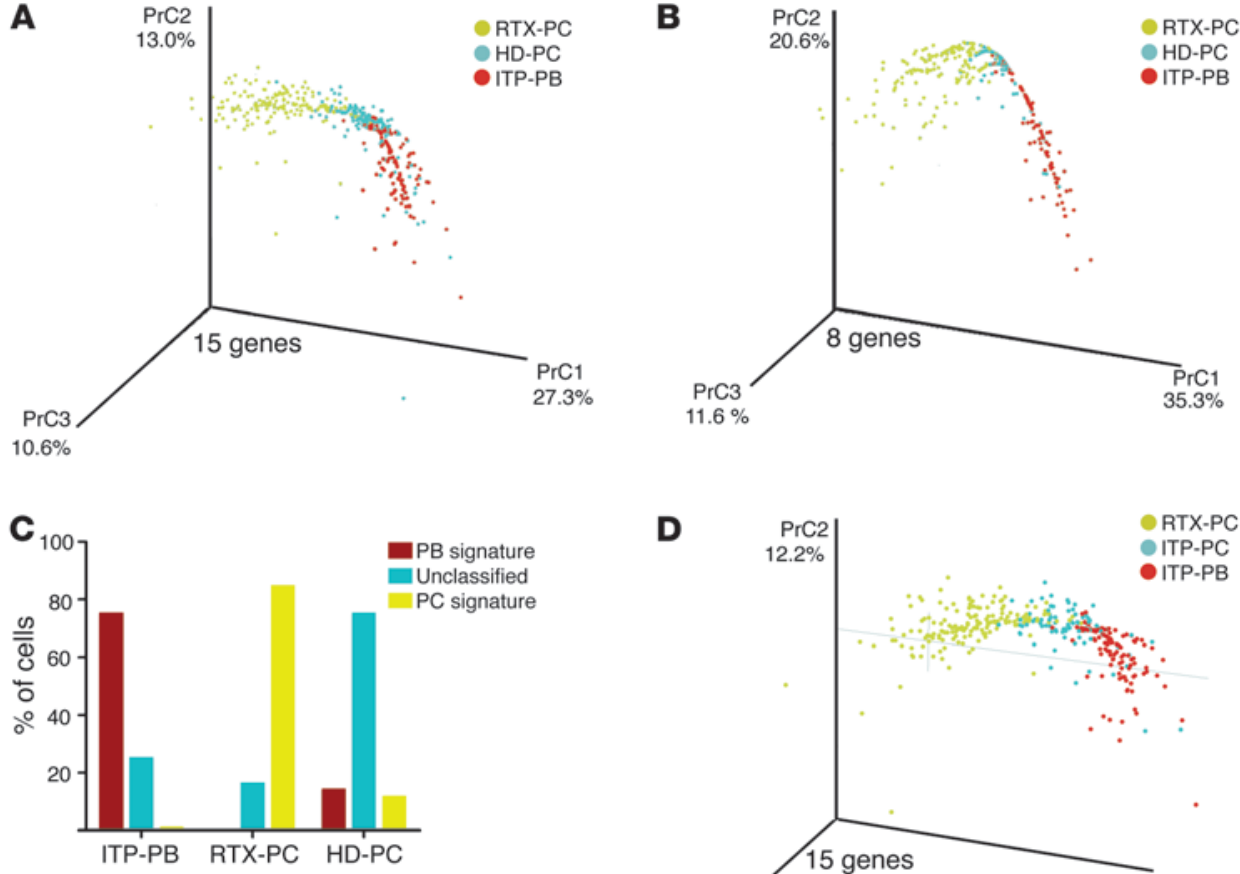

\section{Figure 4}

The intermediate gene expression profile of HD-PC and ITP-PC compared with RTX-PC and ITP-PB is a cell-intrinsic characteristic. Multiplex single-cell PCR was performed with the Fluidigm Dynamic Array on RTX-PC, ITP-PB and HD-PC using 15 genes showing differential expression between RTX-PC and ITP-PB (BIRC5, BUB1, MKI67, ZWINT, CDC6, CCND2, CENPF, KLF6, KLF9, FOS, TNFAIP3, $B I R C 3, A T F 3, C D 9$, SOCS1). Cells expressing less than 2 genes were excluded from the final analysis. (A) 3D representation of the PCA of 504 single cells analyzed according to these 15 genes. Each dot represents a single cell: red, ITP-PB; yellow, RTX-PC; blue, HD-PC. The Ct value was normalized for each cell with $B 2 M$. (B) 3D PCA view of the same samples according to the expression of 8 genes: 4 "PB genes" (cell cycle genes: BUB1, MKI67, ZWINT, CENPF), highly expressed in ITP-PB and at background level in RTX-PC, and 4 "PC genes" (KLF6, KLF9, TNFAIP3, ATF3), highly expressed in RTX-PC and expressed at a low level in ITP-PB. (C) A simplified classification of each cell analyzed using the 8 genes defined above to classify cells with a "PB signature" ( $>1$ cell cycle gene and $\leq 1$ PC genes) or a "PC signature" (no cell cycle gene and >1 PC genes) or as "unclassified." (D) 3D PCA view of ITP-PC together with ITP-PB and RTX-PC analyzed according to the 15 genes defined above.

spleens (Figure 6D). Nevertheless, addition of CCL2 to the in vitro culture did not modify ASC survival (data not shown). By contrast, addition of BAFF to the culture of total spleen cells from HDs increased the ASC survival by an average of 8 fold $(P<0.01)$ (Figure $6 \mathrm{E})$. We concluded that a proinflammatory environment, capable of increasing the ASC survival, may be driven by CCL2 and that the higher concentration of BAFF observed for rituximab spleen sample might selectively contribute to the survival of the resident RTX-PC population.

\section{Discussion}

Splenectomy performed in patients with ITP represents a unique opportunity to study the different partners involved in an autoimmune process. Here, we explored the short- and longlived ASC involved in different pathogenic settings as well as in normal conditions.

We found that, while normal adult spleen displays scarcely any GCs, patients with ITP showed an ongoing immune response with
We inferred that the PC observed in rituximab-treated spleens were made previous to the treatment, i.e., at least 3 to 6 months before splenectomy, and postulated that they could be long lived. The surface analysis of these splenic PC showed that they shared several markers with PC from normal bone marrow (HLA-DR ${ }^{\text {lo }}$ CD9 $\left.{ }^{+} \mathrm{Ki}-67^{-}\right)$. They differed from their bone marrow counterparts by expressing CD11a and CD86 and being negative for CD138. As such, they appeared similar to the PC previously described by Tangye and colleagues in normal human spleen $(4,27)$, with the additional information that they could be dated in this precise therapeutic setting. However, when rituximab-treated splenic $\mathrm{PC}$ were compared at the transcriptomic level with PC isolated from normal spleens and also with PB and PC extracted from the spleens of patients with ITP not treated with rituximab, the situation appeared more complex.

Transcriptomic analyses have so far focused mainly on bone marrow PC or on in vitro generated PB and PC in humans (29-31). By analyzing the short-lived PB in patients with ITP and the long- 

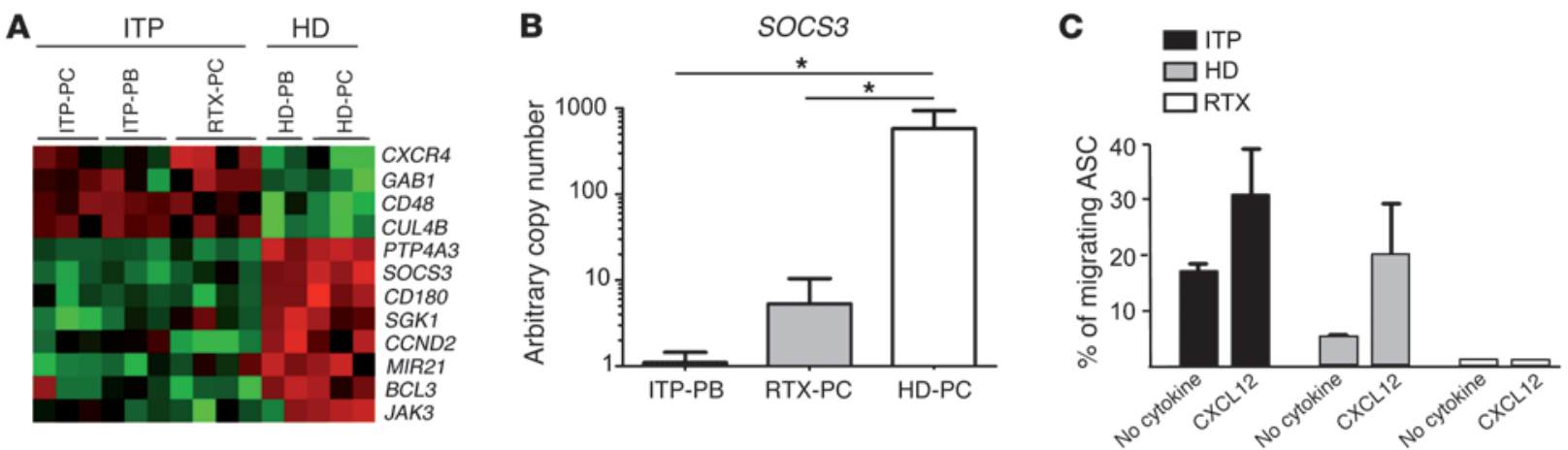

\section{Figure 5}

Splenic ASC from patients with ITP display a specific genetic signature characterized by downregulation of SOCS3. (A) Selected genes showing significant difference in expression between ASC from disease samples (ITP-PC, RTX-PC, ITP-PB) compared with ASC from HDs (HD-PB and HD-PC) $(n=158$; fold change, $>2$ or $<0.5 ; P<0.01)$. Gene expression profiling was performed using Affymetrix U133 Plus 2.0 microarrays after cDNA preamplification. (B) Enhanced expression of suppressor of cytokine signaling 3 (SOCS3) in HD compared with samples of patients with ITP. SOCS3 expression was determined by real-time quantitative RT-PCR, with values normalized for B2M expression. Mann-Whitney test $\left({ }^{*} P<0.05\right)$. (C) Migration of ASC toward CXCL12 in a transwell migration assay. $1 \times 10^{6}$ cells from ITP $(n=2)$, HD $(n=2)$, and rituximab $(n=2)$ splenic samples were cultured overnight in triplicates. The ASC populations were gated as CD3-CD $19^{+}$CD2 $7^{+}$CD $38^{\text {hi }}$ cells, and the proportion of migrating cells was estimated compared with the total number of cells. Mean \pm SEM.

lived PC in rituximab-treated patients, we provided for the first time in humans, the comparison of the two opposite sides of the in vivo ASC genetic program. Splenic RTX-PC presented a bona fide long-lived program very similar to the one of bone marrow PC, characterized by a strong expression of antiapoptotic factors and of negative regulators of the cell cycle, including multiple members of the Krüppel-like factor family, of the AP-1 family, and of genes involved in the unfolded protein response (30-34). In contrast, $\mathrm{PB}$ overexpressed positive regulators or markers of the cell cycle.

When compared with RTX-PC, surprisingly, normal splenic PC displayed an intermediate profile with the expression of some antiapoptotic genes shared with long-lived PC and some cell cycle genes expressed by PB. To unravel whether normal PC were a mixture of several populations or represented a distinct PC differentiation stage, their transcriptomic profile was analyzed at the single-cell level and compared with single PC and PB isolated from patients with ITP, treated or not with rituximab. Based on a small group of genes differentially expressed by PB or long-lived PC, this analysis showed that most of the normal splenic PC showed a genetic profile with a mixed $\mathrm{PC}$ and $\mathrm{PB}$ signature. Interestingly, PC from patients with ITP not treated with rituximab also displayed, at the single-cell level, an intermediate phenotype with the expression of long-lived PC and PB genes, suggesting that the inflammatory environment of the ITP spleen does not favor the formation of PC with a long-lived phenotype.

The gene expression profiles described here are intriguing because they suggest at first that normal splenic PC may display some characteristics of a long-lived program, while keeping at the same time the capacity to enter into proliferation. Such cellular divisions have never been described for PC, but they may occur at a very low rate in defined homeostatic situations. Whether these PC that have kept some PB characteristics can still migrate to other lymphoid sites also remains an open question (29). These data also suggest that the human spleen in an autoimmune inflammatory environment is not a niche for long-lived PC. An alternative explanation for the absence of long-lived splenic PC in the ITP set- ting could be the ongoing production of $\mathrm{PB}$ and $\mathrm{PC}$ that would prevent their local accumulation. Our observation seems to differ from the one in lupus-prone NZBxNZW mice, in which splenic $\mathrm{PC}$, which are in large excess as compared with control animals (5), have differentiated into long-lived PC in the absence of any B cell-depleting therapy. In the human autoimmune setting that we described, which may be quite different from the previous mouse model in which there is a genetic predisposition for an ongoing autoimmune reaction, the total number of $\mathrm{PC}$ is in fact within the same range in ITP and rituximab-treated spleens. This result argues against the survival of a few PC present in ITP spleen that would already possess the long-lived characteristics but rather suggests that the rituximab-treated human spleen in ITP provides a unique environment in which rituximab-resistant ASC can differentiate into bona fide long-lived PC. Interestingly, B cell depletion in healthy mice, either by irradiation (2) or by anti-B cell antibody treatment (35), also triggered the establishment of splenic long-lived PC, suggesting that it is possibly the absence of B cells and the resulting excess of accessory cells or cytokines necessary for PC survival, such as BAFF (see below), which may be responsible for this phenomenon. These results may bear some clinical relevance, since they would suggest that treatment with rituximab may paradoxically induce in certain situations the differentiation of autoimmune PC into long-lived resident cells.

Stromal cells, eosinophils, and megakaryocytes secreting CXCL12, IL-6, and APRIL have been shown to interact with long-lived PC in bone marrow, and IL-6-secreting basophils and stromal cells have been shown to interact with PC in the spleen $(27,36-41)$. A specific inflammatory milieu could promote the residence of long-lived $\mathrm{PC}$ in rituximab-treated patients, since RTX-PC survived better than control ones upon in vitro incubation of total splenic cells. A multiplex cytokine analysis of these culture supernatants revealed an increase in secretion of CCL2, a chemokine with the potential to attract monocytes, neutrophils, and basophils $(42,43)$, an increase that was, however, common to the ITP and rituximab treatment conditions. Accordingly, basophil numbers were markedly enhanced in both cases. The 
A

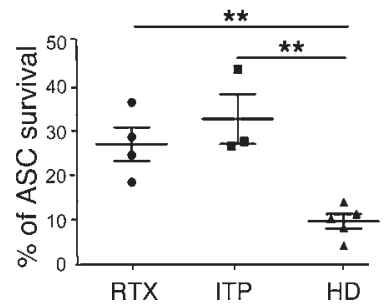

D

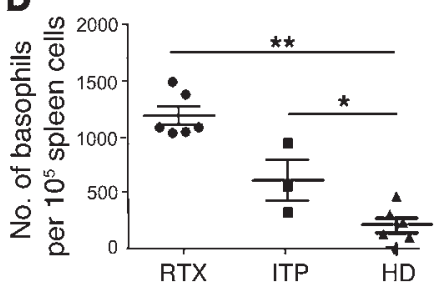

\section{Figure 6}

ASC in ITP display a prolonged in vitro survival within a specific cytokinic and cellular microenvironment. (A) ASC survival after 5-day culture. Survival was estimated by the fraction of input ASC detectable after 5-day culture of $5 \times 10^{5}$ spleen cells in triplicate, estimated by an anti-Ig ELISPOT (mean survival, RTX: $26.4 \% \pm 3.7 \%$; ITP: $32 \% \pm 9.5 \%$; HD: $9.3 \% \pm 1.6 \%$ ). (B) BAFF concentration in spleen supernatants after 5 -day culture. BAFF concentration was estimated by ELISA in culture medium of $10^{5}$ spleen cells cultured in triplicates for 5 days (mean BAFF secretion, RTX: $33.6 \pm 6.2 \mathrm{pg} / \mathrm{ml}$; ITP: $7.2 \pm 1.2 \mathrm{pg} / \mathrm{ml}$; HD: $20.2 \pm 1$ $\mathrm{pg} / \mathrm{ml}$ ). (C) CCL2 concentration in spleen supernatants after 5-day culture. CCL2 concentration was estimated as part of a multiplex 27-cytokine assay in spleen supernatants of $10^{5}$ cells cultured in triplicate for 5 days (mean CCL2 secretion, RTX: $11,410 \pm 228 \mathrm{pg} / \mathrm{ml}$; ITP: $11,410 \pm 1,236 \mathrm{pg} / \mathrm{ml}$; HD: 3,233 $\pm 1,927 \mathrm{pg} /$ $\mathrm{ml}$ ). (D) Number of basophils in ITP and rituximab spleens. Spleen basophils were estimated by flow cytometry as numbers of HLA-DR-CD123+FceRI ${ }^{\text {hi }}$ cells per $10^{5}$ cells (mean basophil numbers, RTX: 1,162 \pm 79.8 ; ITP: $591 \pm 178.4$; HD: $201 \pm 64.5)$. (E) ASC survival from HD spleens after culture with or without BAFF (100 $\mathrm{ng} / \mathrm{ml}$ ). Survival was estimated as in A. The values obtained with or without BAFF for each sample are connected by a straight line (median fold increased survival with BAFF: 8.3 [3.2-23]). Significant differences estimated by Mann-Whitney and paired $t$ test $\left({ }^{\star *} P<0.01,{ }^{*} P<0.05\right)$. Symbols indicate individual samples; horizontal bars represent mean values $( \pm$ SEM).

\section{Methods}

Patients with ITP and healthy controls

Patients with ITP. All patients included fulfilled the following criteria: age, $\geq 18$ years; ITP diagnosis according to the American Society Hematology guidelines. Exclusion criteria were as follows: other disease(s) associated with ITP (immunodeficiency, hepatitis C virus infection, lymphoproliferative disorders, thyroid or liver disease, and definite systemic lupus erythematosus [ $\geq 4$ American Rheumatism Association criteria]). Evan's syndrome has also been excluded. Response rate to splenectomy was defined according to the international criteria: complete response (defined as a platelet count $\left.>100 \times 10^{9} / 1\right)$; primary platelet response (defined as a platelet count $\geq 50 \times 10^{9} / 1$, with at least the doubling of the baseline value without any rescue intervention during the preceding 8 weeks); and no response (defined as a platelet count $\left.<50 \times 10^{9} / 1\right)$. Blood samples were obtained for 4 RTX-treated patients at the time of splenectomy.

Controls. The characteristics of the subjects, including age and sex, at the time of sample collection, are

main differences in cytokine secretion concerned IL-6 and BAFF, whose secretion was increased in ITP and rituximab-treated spleen supernatants, respectively. The increase in BAFF secretion could be a direct consequence of $B$ cell depletion $(44,45)$ and might constitute a key factor, allowing, together with other players, for the settlement of long-lived PC in the rituximab-treated spleen.

Many questions remain unanswered in antibody-mediated autoimmune diseases such as ITP. What drives the intense GC reaction and $\mathrm{PB}$ production in the ITP spleen, also described in many other target organs of human autoimmune diseases, since only a small percentage of the PC produced seem to secrete autoantibodies? As recently highlighted, inflammatory B cells producing cytokines such as IL-6 may promote this local B cell activation, but the mechanism of tolerance breakdown remains unknown (46). Finally, a straight forward proposition coming out of these results is that ITP may be caused either by autoimmune CD $20^{+}$memory B cells and the short-lived $\mathrm{PB}$ and $\mathrm{PC}$ they produce (response to rituxi$\mathrm{mab}$ ) or by long-lived $\mathrm{CD}^{2} 0^{-}$pathogenic $\mathrm{PC}$ present in the spleen (response to splenectomy after rituximab failure) or in other lymphoid niches (47) (failure of both treatments). One future therapeutic goal in ITP could be, according to our results, to modulate the splenic microenvironment, such as with an anti-BAFF therapy associated with rituximab, in order to prevent the generation of splenic long-lived PC. detailed in Supplemental Table 2. All died from stroke. None presented with lymphoma or known autoimmune disease.

\section{Confocal microscopy analysis of human spleens}

Immediately after splenectomy, pieces of splenic tissue were excised and embedded in OCT (Sakura), snap frozen in liquid nitrogen, and stored at $-80^{\circ} \mathrm{C}$. Cryosections $(7-9 \mu \mathrm{m})$ were cut, fixed in cold $\left(-20^{\circ} \mathrm{C}\right)$ acetone for 10 minutes, rehydrated in wash buffer (TBS, pH 7.6), and incubated in blocking buffer (0.5\% BSA and 10\% goat serum in PBS) for 30 minutes at room temperature. Sections were then incubated for 60 minutes at room temperature, with the indicated primary antibodies in the blocking buffer solution (see Supplemental Table 3 for a complete list of antibodies). Incubations without primary antibodies were used as control. Sections were washed 3-4 times and incubated with the secondary antibody as indicated (30 minutes at room temperature). Sections were washed and mounted in Fluoromont-G (Southern Biotech). Images were acquired by confocal microscopy with a LSM 700 (Zeiss). Fluorescence of single channels was measured, and control reference was systematically done. Pictures were taken with an objective $\times 40$. Images were analyzed and processed with ImageJ version 1.46 .

\section{Flow cytometry and cell sorting}

Antibodies used are listed in Supplemental Table 3. Intracellular staining was performed after cell fixation and permeabilization with the BD Cyto- 
fix/Cytoperm solution. Stained populations were analyzed on a FACSCantoII apparatus with the DIVA or FlowJo software. Cell sorting was performed with a FACSAria cell sorter (Becton Dickinson), and gates were set to collect the $\mathrm{CD} 19^{+} \mathrm{CD} 20^{-} \mathrm{CD} 27^{+} \mathrm{CD} 38^{\text {hi }} \mathrm{HLA}-\mathrm{DR}{ }^{\text {lo }}(\mathrm{PC})$ and HLA-DR ${ }^{\text {hi }}$ $(\mathrm{PB})$ fractions in $\mathrm{HDs}$ and patients with ITP and $\mathrm{CD} 3{ }^{-} \mathrm{CD} 19^{+} \mathrm{CD} 27^{+} \mathrm{CD} 38^{\text {hi }}$ cell fractions in patients treated with anti-CD20. The cell purity after sorting was greater than $99 \%$.

\section{ELISPOT assays}

Anti-GPIIbIIIa IgG PC detection. Multiscreen 96-well filter plates (MSIPS4510; Millipore) were coated by incubation overnight at $4^{\circ} \mathrm{C}$ with $2.5 \mu \mathrm{g} / \mathrm{ml} \mathrm{key-}$ hole limpet hemocyanin $(\mathrm{KLH}), 10 \mu \mathrm{g} / \mathrm{ml}$ goat anti-human Ig polyvalent antibody (Invitrogen), or $30 \mu \mathrm{g} / \mathrm{ml}$ purified GpIIbIIIa (Kordia Science) and coated in $\mathrm{PBS} / \mathrm{CaCl} 20.05 \% .1 \times 10^{6}$ cells were serially diluted in culture medium in triplicate before transfer to ELISPOT plates and cultured 4-6 hours in complete culture medium at $37^{\circ} \mathrm{C}$ under an atmosphere containing $5 \% \mathrm{CO}_{2}$. The ELISPOT was revealed with biotinylated goat anti-human IgG Fc (Invitrogen), followed by HRP-conjugated avidin (Vector Laboratories) and developed using 3-amino-9-ethylcarbazole (Sigma-Aldrich). Spots were counted in wells showing more than 3 specific spots in an ELISPOT reader with the AID software (version 3.5; AutoImmun Diagnostika). When detected, IgG-secreting anti-GpIIbIIIa spot numbers were reported to IgG-positive spots. When no specific spot was detectable, a value "less than $x$ " was assigned, with $x$ corresponding to the frequency obtained if 1 GpIIbIIIa spot were detected at the lowest dilution.

PC survival. After spleen cultures, IgG-, IgA-, and IgM-secreting cells were assessed to estimate ASC survival. Briefly, $0.5 \times 10^{6}$ to $1 \times 10^{6}$ cells were either serially diluted in 96-well filter plates and cultured for 6 hours or were cultured 5 days in $1 \mathrm{ml}$ complete culture medium at $37^{\circ} \mathrm{C}$ in triplicate in a 24-well plate before serial dilutions. The ELISPOT was revealed as described above. The ratio of ASC detected between day 5 and day 0 was used as an estimate of in vitro ASC survival. In some experiments, human recombinant BAFF (Peprotech, $100 \mathrm{ng} / \mathrm{ml}$ ) was added in the culture from splenic HD.

\section{Cytokine assays}

Culture supernatants of $1 \times 10^{6}$ spleen cells per ml plated in 24-well plates were collected at day 5. Quantitative determination of secreted cytokines was performed with the Bio-Rad human cytokine 27-plex assay, carried out according to the manufacturer's instructions. The human TNSF13B/BAFF, CXCL12 (Quantikine, RD systems), and APRIL (USCNK) immunoassays were carried out according to the manufacturer's instructions.

\section{Chemotaxis assay}

Chemotaxis assays were performed using transwell plates (Corning). CXCL12 (Peprotech) was added to wells of a 24-well plate at $100 \mathrm{ng} / \mathrm{ml} .1 \times 10^{6}$ spleen cells were cultured overnight in the upper well. The migrating ASC population was estimated by FACS as CD3-CD $19^{+} \mathrm{CD} 27^{+} \mathrm{CD} 38^{\text {hi }}$ cells present in the lower well. The chemotaxic index was calculated as the number of cells migrating in the presence of chemokines versus the total number of cells.

\section{Gene expression profiling}

RNA was isolated from sort-purified $\mathrm{PC}\left(\mathrm{CD} 19^{+} \mathrm{CD} 20^{-} \mathrm{CD} 27^{+} \mathrm{CD} 38^{\text {hi }}\right.$ HLA-DR $\left.{ }^{\text {lo }}\right)$ and $\mathrm{PB}\left(\mathrm{CD} 19^{+} \mathrm{CD} 20^{-} \mathrm{CD} 27^{+} \mathrm{CD} 38^{\text {hi }} \mathrm{HLA}-\mathrm{DR}{ }^{\mathrm{lo}}\right)$ from 3 spleens of HDs and of patients with ITP (ITP1, ITP2, ITP3). PC (CD3-CD19+CD27+ CD38 ${ }^{\text {hi }}$ ) were isolated from 4 spleens of rituximab-treated patients (RTX1, RTX2, RTX6, RTX8). Total RNA was isolated using the RNeasy Micro Kit (QIAGEN). RNA quality and concentration were assessed using RNA 6000 Pico LabChips with a 2100 Bioanalyzer (Agilent Technologies). Total RNA (10 ng) was preamplified by Ribo-SPIA (Ribo-single primer isothermal amplification) RNA Amplification using the Ovation Pico WTA Kit (NuGEN
Technologies), fragmented, and labeled with biotin using the Encore Biotin Module (NuGEN Technologies), as recommended by the manufacturer. Expression analysis was performed using GeneChip Human U133 Plus 2.0 Arrays (Affymetrix). Gene expression levels were calculated using GCRMA, and flags were computed using MAS5 within R. To limit potentially biased measurements (background or saturating), all probes whose flags were absent or marginal were flagged as 0 , whereas those present were flagged as 1 . The group comparisons were done using a Student's $t$ test. To estimate the false discovery rate, we filtered the resulting $P$ values at 0.05 (or 0.01 in certain cases) and considered data with 2- or 4-fold changes between samples. Data were subsequently compared to the gene ontology database (http://www. geneontology.org/). Complete data sets have been deposited in EMBL-EBI database (http://www.ebi.ac.uk/arrayexpress/; accession no. E-MEXP-3711).

\section{Single-cell gene expression analysis}

Single splenic PC from 2 HDs and 2 rituximab-treated patients and single $\mathrm{PB}$ and PC from 2 patients with ITP were isolated by cell sorting. Cells were sorted in $5 \mu \mathrm{l}$ of buffer containing the RT-PCR reagents and the preamplification primers (CellsDirect One-Step qRT-PCR mix, SuperScriptIII RT/Platinum TaqMix $2 \%$, and TaqMan primers $(\times 0.005)$ [Applied Biosystems]). A list of primers is available in Supplemental Table 4. After reverse transcription and gene-specific preamplification, cDNAs were diluted 5 times and kept frozen at $-20^{\circ} \mathrm{C} .10 \times$ primer solutions were prepared with $2 \times$ Assay Loading Reagent (Fluidigm). cDNA were mixed with TaqMan Universal PCR Master Mix 2× (Applied Biosystems) and ×20 GE Sample Loading Reagent (Fluidigm). Assay mix and cDNA mix were then transferred in a 48.48 Dynamic Array primed chip, and real-time PCR was run according to the Fluidigm protocol. 100-cell and no-cell wells were used as positive and negative control, respectively. Data were analyzed using Fluidigm Real-Time PCR analysis software. HLA-DRB1, CD38, CD27, and $C D 3$ genes were used as control genes. To limit potentially biased measurements, cells with less than 2 expressed genes among the 15 selected diagnostic genes were excluded from the analysis. PCA was performed with GeneSpring analysis software. PCA was performed with and without normalization of the $\mathrm{Ct}$ value for each gene with the B2M housekeeping gene.

\section{Statistics}

Statistical comparisons were made with the nonparametric Mann-Whitney test, and the Wilcoxon signed-rank test was used for paired samples using GraphPad Prism. A $P$ value of $\leq 0.05$ was considered as significant.

\section{Study approval}

The study was approved by the Agence de la Biomédecine and the Comité de Protection des Personnes (CPP) Ile de France-II for controls and by the CPP Ile de France-IX for patients with ITP. This study was conducted in accordance with the Helsinki Declaration, with informed consent obtained from each patient with ITP for collecting splenic samples.

\section{Acknowledgments}

We are grateful to S. Weller and S. Stork for helpful discussions. We thank L. Da Silva for technical support, J. Mégret and C. Cordier for cell sorting, C. Copie for histological analysis, and N. Goudin for confocal microscopy. We thank the Centre d'Immunologie Humaine (Institut Pasteur) for providing access to the Fluidigm technology. We also thank the other physicians whose patients were included in this study: C. Fieschi, E. Oksenhendler, N. Schleinitz, J.M. Michot, and L. Languille. INSERM U783 is supported by the Ligue Nationale contre le Cancer ("Equipe labelisée"), the Fondation Princesse Grace, and an ERC advanced investigator grant. Matthieu Mahévas was supported by a fellowship from the 
Fondation pour la Recherche Médicale, the "Société de Médecine Interne" (Bourse Marcel Simon), and a Poste d'Accueil INSERM. Pauline Patin was supported by a fellowship from the Fondation Bettencourt-Schueller ("Ecole de l'INSERM-Liliane Bettencourt").

Received for publication July 6, 2012, and accepted in revised form October 11, 2012.

1. Manz RA, Thiel A, Radbruch A. Lifetime of plasma cells in the bone marrow. Nature. 1997; 388(6638):133-134.

2. Slifka MK, Antia R, Whitmire JK, Ahmed R. Humoral immunity due to long-lived plasma cells. Immunity. 1998;8(3):363-372.

3. Amanna IJ, Carlson NE, Slifka MK. Duration of humoral immunity to common viral and vaccine antigens. N Engl J Med. 2007;357(19):1903-1915.

4. Ellyard JI, Avery DT, Phan TG, Hare NJ, Hodgkin PD, Tangye SG. Antigen-selected, immunoglobulin-secreting cells persist in human spleen and bone marrow. Blood. 2004;103(10):3805-3812.

5. Hoyer BF, et al. Short-lived plasmablasts and longlived plasma cells contribute to chronic humoral autoimmunity in NZB/W mice. J Exp Med. 2004; 199(11):1577-1584.

6. Hiepe F, Dorner T, Hauser AE, Hoyer BF, Mei H, Radbruch A. Long-lived autoreactive plasma cells drive persistent autoimmune inflammation. Nat Rev Rheumatol. 2011;7(3):170-178.

7. Cines DB, Bussel JB, Liebman HA, Luning Prak ET. The ITP syndrome: pathogenic and clinical diversity. Blood. 2009;113(26):6511-6521.

8. Cooper N, Bussel J. The pathogenesis of immune thrombocytopaenic purpura. Br J Haematol. 2006; 133(4):364-374.

9. Kuwana M, Kaburaki J, Ikeda Y. Autoreactive T cells to platelet GPIIb-IIIa in immune thrombocytopenic purpura. Role in production of anti-platelet autoantibody. J Clin Invest. 1998; 102(7):1393-1402.

10. Kuwana M, Okazaki Y, Ikeda Y. Splenic macrophages maintain the anti-platelet autoimmune response via uptake of opsonized platelets in patients with immune thrombocytopenic purpura. J Thromb Haemost. 2009;7(2):322-329.

11. Stasi R, Provan D. Management of immune thrombocytopenic purpura in adults. Mayo Clin Proc. 2004; 79(4):504-522.

12. Kojouri K, Vesely SK, Terrell DR, George JN. Splenectomy for adult patients with idiopathic thrombocytopenic purpura: a systematic review to assess long-term platelet count responses, prediction of response, and surgical complications. Blood. 2004; 104(9):2623-2634.

13. Godeau B, et al. Rituximab efficacy and safety in adult splenectomy candidates with chronic immune thrombocytopenic purpura: results of a prospective multicenter phase 2 study. Blood. 2008; 112(4):999-1004.

14. Patel VL, et al. Outcome at 5 years following response to rituximab therapy in children and adults with immune thrombocytopenia (ITP). Blood. 2012;119(25):5989-5995.

15. Auger S, Duny Y, Rossi JF, Quittet P. Rituximab before splenectomy in adults with primary idio-

Address correspondence to: Claude-Agnès Reynaud or Jean-Claude Weill, Faculté de Médecine, Site Necker-Enfants Malades, INSERM U783 Développement du système immunitaire, Université Paris Descartes, 156 rue de Vaugirard, 75730 Paris Cedex 15, France. Phone: 33.1.40615683; Fax: 33.1.40615590. E-mail: claude-agnes. reynaud@inserm.fr (C.A. Reynaud), jean-claude.weill@inserm.fr (J.C. Weill).

pathic thrombocytopenic purpura: a meta-analysis. Br J Haematol. 2012;158(3):386-398.

16. Hamaguchi $\mathrm{Y}$, et al. The peritoneal cavity provides a protective niche for $\mathrm{B} 1$ and conventional B lymphocytes during anti-CD20 immunotherapy in mice. J Immunol. 2005;174(7):4389-4399.

17. Ahuja A, Shupe J, Dunn R, Kashgarian M, Kehry MR, Shlomchik MJ. Depletion of B cells in murine lupus: efficacy and resistance. J Immunol. 2007; 179(5):3351-3361.

18. Gong Q, et al. Importance of cellular microenvironment and circulatory dynamics in B cell immunotherapy. J Immunol. 2005;174(2):817-826.

19. Huang H, Benoist C, Mathis D. Rituximab specifically depletes short-lived autoreactive plasma cells in a mouse model of inflammatory arthritis. Proc Natl Acad Sci U S A. 2010;107(10):4658-4663.

20. Edwards JC, Cambridge G. B-cell targeting in rheumatoid arthritis and other autoimmune diseases. Nat Rev Immunol. 2006;6(5):394-403.

21. Lund FE, Randall TD. Effector and regulatory B cells: modulators of CD4(+) T cell immunity. Nat Rev Immunol. 2010;10(4):236-247.

22. Mei HE, et al. Steady-state generation of mucosal IgA+ plasmablasts is not abrogated by B-cell depletion therapy with rituximab. Blood. 2010;116(24):5181-5190.

23. Fagerli UM, et al. Overexpression and involvement in migration by the metastasis-associated phosphatase PRL-3 in human myeloma cells. Blood. 2008;111(2):806-815.

24. Le Y, et al. SOCS3 protein developmentally regulates the chemokine receptor CXCR4-FAK signaling pathway during B lymphopoiesis. Immunity. 2007; 27(5):811-823.

25. Soriano SF, et al. Functional inactivation of CXC chemokine receptor 4-mediated responses through SOCS3 up-regulation. J Exp Med. 2002; 196(3):311-321.

26. Jones SA, White CA, Robb L, Alexander WS, Tarlinton DM. SOCS3 deletion in B cells alters cytokine responses and germinal center output. J Immunol. 2011;187(12):6318-6326.

27. Ellyard JI, Avery DT, Mackay CR, Tangye SG. Contribution of stromal cells to the migration, function and retention of plasma cells in human spleen: potential roles of CXCL12, IL-6 and CD54. Eur J Immunol. 2005;35(3):699-708.

28. Audia $S$, et al. Immunologic effects of rituximab on the human spleen in immune thrombocytopenia. Blood. 2011;118(16):4394-4400.

29. Yoshida T, et al. Memory B and memory plasma cells. Immunol Rev. 2010;237(1):117-139.

30. Jourdan $M$, et al. An in vitro model of differentiation of memory B cells into plasmablasts and plasma cells including detailed phenotypic and molecular characterization. Blood. 2009;114(25):5173-5181.

31. Jourdan M, et al. Characterization of a transitional preplasmablast population in the process of human B cell to plasma cell differentiation. J Immunol. 2011;187(8):3931-3941.

32. Oracki SA, Walker JA, Hibbs ML, Corcoran LM, Tarlinton DM. Plasma cell development and survival. Immunol Rev. 2010;237(1):140-159.

33. Hart GT, Hogquist KA, Jameson SC. Kruppel-like factors in lymphocyte biology. J Immunol. 2012; 188(2):521-526.

34. Good KL, Tangye SG. Decreased expression of Kruppel-like factors in memory B cells induces the rapid response typical of secondary antibody responses. Proc Natl Acad Sci US A. 2007;104(33):13420-13425.

35. Ahuja A, Anderson SM, Khalil A, Shlomchik MJ. Maintenance of the plasma cell pool is independent of memory B cells. Proc Natl Acad Sci U S A. 2008; 105(12):4802-4807.

36. Chu VT, et al. Eosinophils are required for the maintenance of plasma cells in the bone marrow. Nat Immunol. 2011;12(2):151-159.

37. Winter $\mathrm{O}$, et al. Megakaryocytes constitute a functional component of a plasma cell niche in the bone marrow. Blood. 2010;116(11):1867-1875.

38. Tokoyoda K, Egawa T, Sugiyama T, Choi BI, Nagasawa T. Cellular niches controlling B lymphocyte behavior within bone marrow during development. Immunity. 2004;20(6):707-718.

39. Cassese G, et al. Plasma cell survival is mediated by synergistic effects of cytokines and adhesion-dependent signals. J Immunol. 2003;171(4):1684-1690.

40. Minges Wols HA, Underhill GH, Kansas GS, Witte PL. The role of bone marrow-derived stromal cells in the maintenance of plasma cell longevity. J Immunol. 2002;169(8):4213-4221.

41. Rodriguez Gomez M, Talke Y, Goebel N, Hermann F, Reich B, Mack M. Basophils support the survival of plasma cells in mice. J Immunol. 2010; 185(12):7180-7185

42. Moser B, Wolf M, Walz A, Loetscher P. Chemokines: multiple levels of leukocyte migration control. Trends Immunol. 2004;25(2):75-84.

43. Iikura $M$, et al. Transendothelial migration of human basophils. J Immunol. 2004;173(8):5189-5195.

44. Kreuzaler M, et al. Soluble BAFF levels inversely correlate with peripheral $B$ cell numbers and the expression of BAFF receptors. J Immunol. 2012; 188(1):497-503.

45. Sarantopoulos S, et al. Recovery of B-cell homeostasis after rituximab in chronic graft-versus-host disease. Blood. 2011;117(7):2275-2283.

46. Barr TA, et al. B cell depletion therapy ameliorates autoimmune disease through ablation of IL-6-producing B cells. J Exp Med. 2012;209(5):1001-1010.

47. Kuwana M, Iki S, Urabe A. The role of autoantibody-producing plasma cells in immune thrombocytopenic purpura refractory to rituximab. Am J Hematol. 2007;82(9):846-848. 